\title{
Broadband cross dipole antenna for UHF near-field RFID applications
}

\author{
Zhengyong $\mathrm{Yu}^{1 \text {, a) }}$, Cheng Huang ${ }^{2, \mathrm{~b})}$, Yihan $\mathrm{Xu}^{1}$, and Yan Jiang ${ }^{3}$
}

Abstract A broadband cross dipole antenna for ultra-high frequency (UHF) near-field radio frequency identification (RFID) applications is proposed in this paper. The proposed antenna with two perpendicular coplanar dipoles can identify the tags that placed random perpendicularly to the antenna's surface. A prototype is fabricated and tested for verification. By adjusting the length of one dipole, the broadband characteristic is obtained. Measured results show that the operating bandwidth $\left(\mathrm{S}_{11}<-10 \mathrm{~dB}\right)$ is about $210 \mathrm{MHz}$ from 852 to $1062 \mathrm{MHz}$. Meanwhile, a strong and uniform magnetic-field distribution surrounding the antenna is achieved with an interrogation zone of $142 \mathrm{~mm} \times 142 \mathrm{~mm}$.

Keywords: ultra-high frequency (UHF), near field, radio frequency identification (RFID), broadband cross dipole, antenna

Classification: Microwave and millimeter-wave devices, circuits, and modules

\section{Introduction}

With the explosive development of Internet of Things (IoT), radio frequency identification (RFID), as one of the key technologies, has received more and more attention $[1,2,3$, $4,5]$. Based on the operating principle, the RFID system can be classified into near-field and far-field system. The nearfield system usually works by the inductive coupling at low frequency (LF) or high frequency (HF). While, the far-field system realizes the high read rate and long identification distance through the propagation mechanism at ultra-high frequency (UHF) or micro-wave (MW) band, which means that the tags cannot be directly attached to the metal surface. To obtain the advantages of the near-field and far-field system simultaneously, the UHF near-field RFID system has become the research focus $[6,7,8,9,10,11]$.

As the most common type of the near-field RFID reader antenna, loop antenna is the first choice to be used at UHF band $[12,13,14,15,16,17,18,19,20,21,22,23,24,25$, 26, 27, 28, 29, 30, 31]. However, due to the inverse current, the conventional loop antenna could generate the blind area. Therefore, many researchers have been studied to modify the electrically-large loop antenna, such as segmented loop

${ }^{1}$ School of Computer and Communication, Jiangsu Vocational College of Electronics and Information, Huai'an, 223003, China

${ }^{2}$ School of Electronic and Optical Engineering, Nanjing University of Science and Technology, Nanjing, 210094, China

${ }^{3}$ School of Physics and Technology, Nanjing Normal University, Nanjing 210023, China

a) yonglly@ sina.com

b) huangcheng1029@qq.com

DOI: 10.1587/elex.17.20200398

Received November 24, 2020

Accepted December 21, 2020

Publicized December 28, 2020

Copyedited January 25, 2021 antenna with lumped capacitors [12], zero-phase-shift line (ZPSL) [13, 14, 15, 16, 17, 18, 19, 20, 21, 22, 23, 24], several dipoles to form the loop antenna [25, 26, 27, 28, $29]$ and other modified loop antenna [30, 31]. The other popular type of UHF near-field reader antenna is based on the oppositely directed currents (ODCs) [32, 33, 34, 35, $36,37,38]$. These researches mainly focused on how to generate an uniform magnetic-field distribution at a large interrogation zone. Meanwhile, it can be found that all of them are based on a basic premise that the tag surface is parallel to the reader antenna surface. So far, only a few studies have been considered the tag placement [39, 40, 41]. For instance, H.-W. Liu et al. utilize curved strips and coupled stubs to identify the tags placed perpendicularly to the antenna surface [40]. Nevertheless, the tags are still placed in the fixed direction.

For more flexible tag placement, a broadband cross dipole antenna is proposed for UHF near-field RFID applications. Through theoretical analysis and formula derivation, the dipole placed along $x$-axis generates such magnetic-field to read the tags placed perpendicularly to the $y$-axis. Similarly, the dipole placed along $y$-axis generates such magneticfield to read the tags placed perpendicularly to the $x$-axis. Thus, the proposed antenna consisting of two perpendicular dipoles can identify the tags placed random perpendicularly to its surface. By optimum design, our proposed antenna covers the global UHF RFID frequency band, and has the interrogation zone of $142 \mathrm{~mm} \times 142 \mathrm{~mm}$.

\section{Antenna configuration}

Fig. 1 demonstrates the top view of the proposed antenna. It is composed of two dipoles placed along $x$-axis and $y$-axis, respectively. The proposed antenna is supported by a square FR4 substrate with thickness $1.6 \mathrm{~mm}$ and relative dielectric constant of 4.4. The physical dimensions denoted in Fig. 1



Fig. 1 Top view of the proposed antenna 
are as follows: $L=160 \mathrm{~mm}, l_{1}=62 \mathrm{~mm}, l_{2}=54 \mathrm{~mm}$, $w_{1}=3 \mathrm{~mm}, w_{2}=1 \mathrm{~mm}, d=2.2 \mathrm{~mm}$, and fed $=1 \mathrm{~mm}$.

\section{Analysis of the proposed antenna}

\subsection{Near-field distribution of the half-wave dipole}

Assuming that the half-wave dipole is placed along $x$-axis, its current distribution can be displayed as follow.

$$
\vec{I}\left(x^{\prime}\right)=\overrightarrow{\mathrm{e}}_{x} \begin{cases}I_{0} e^{j \phi} \sin \left[k\left(\lambda / 4-x^{\prime}\right)\right] ; & 0 \leq x^{\prime} \leq \lambda / 4 \\ I_{0} e^{j \phi} \sin \left[k\left(\lambda / 4+x^{\prime}\right)\right] ; & -\lambda / 4 \leq x^{\prime} \leq 0\end{cases}
$$

Where, $I_{0}$ and $\varphi$ are the maximum current and the initial phase respectively, as well as $k$ equals to $2 \pi / \lambda$. According to the Ampere's Law, the magnetic-field surrounding the dipole is generated as shown in Fig. 2. The dipole only generates the $y$ and $z$ components of magnetic-field $\left(H_{y}, H_{z}\right)$ under the Cartesian coordinate. Meanwhile, it is noted that there are nearly no $H_{z}$ right above the dipole, which means it will has the identify blind area if the tags are placed parallel to the antenna surface as usual. However, there always exists the $y$ component above the dipole.

On the other hand, according to the derivation of Eq. (2), it is used to quantify the magnetic-field that is consistent with the theoretical analysis.

$$
\begin{aligned}
\vec{I} & =\vec{e}_{x} I_{x} \Rightarrow \vec{A}=\vec{e}_{x} A_{x} \\
& \Rightarrow \vec{H}=\frac{1}{\mu} \nabla \times \vec{A}=\frac{1}{\mu}\left|\begin{array}{ccc}
\vec{e}_{x} & \vec{e}_{y} & \vec{e}_{z} \\
\frac{\partial}{\partial x} & \frac{\partial}{\partial y} & \frac{\partial}{\partial z} \\
A_{x} & A_{y} & A_{z}
\end{array}\right| \\
& \Rightarrow \vec{H}=\vec{e}_{y} H_{y}+\vec{e}_{z} H_{z}
\end{aligned}
$$

Combined with Eq. (1) and Eq. (2), the detail magneticfield distribution can be expressed by the following function.

$$
\begin{aligned}
& H_{x}=0 \\
& H_{y}=\frac{1}{\mu} \frac{\partial A_{x}}{\partial z} \\
& =-\frac{I_{0} e^{j \phi}}{4 \pi}\left(\int_{0}^{\lambda / 4} c \times \sin \left[k\left(\lambda / 4-x^{\prime}\right)\right] d x^{\prime}\right. \\
& \left.+\int_{-\lambda / 4}^{0} c \times \sin \left[k\left(\lambda / 4+x^{\prime}\right)\right] d x^{\prime}\right) \\
& H_{z}=-\frac{1}{\mu} \frac{\partial A_{x}}{\partial y} \\
& =\frac{I_{0} e^{j \phi}}{4 \pi}\left(\int_{0}^{\lambda / 4} d \times \sin \left[k\left(\lambda / 4-x^{\prime}\right)\right] d x^{\prime}\right. \\
& \vec{H}=\vec{e}_{y} H_{y}
\end{aligned}
$$

Fig. 2 Magnetic-field of the dipole placed along $x$-axis

$$
\left.+\int_{-\lambda / 4}^{0} d \times \sin \left[k\left(\lambda / 4+x^{\prime}\right)\right] d x^{\prime}\right)
$$

Where,

$$
\begin{aligned}
& c=e^{-j k \sqrt{\left(x-x^{\prime}\right)^{2}+y^{2}+z^{2}}} \frac{z}{\sqrt{\left(x-x^{\prime}\right)^{2}+y^{2}+z^{2}}} \\
& \times\left[1+\frac{j k}{\sqrt{\left(x-x^{\prime}\right)^{2}+y^{2}+z^{2}}}\right] \\
& d=e^{-j k \sqrt{\left(x-x^{\prime}\right)^{2}+y^{2}+z^{2}}} \frac{y}{\sqrt{\left(x-x^{\prime}\right)^{2}+y^{2}+z^{2}}} \\
& \times\left[1+\frac{j k}{\sqrt{\left(x-x^{\prime}\right)^{2}+y^{2}+z^{2}}}\right]
\end{aligned}
$$

With the aid of MATLAB software, the magnetic-field distribution of the half-wave dipole at $920 \mathrm{MHz}$ can be obtained by Eq. (3) and Eq. (4). For comparison, the high frequency structure simulator (HFSS) is used to model the half-wave dipole. Fig. 3 shows the normalized $\left|H_{y}\right|$ distribution along $x$-axis at $z=50 \mathrm{~mm}$. It is observed that the calculated results are well coincided with the simulated ones.

In order to understand the near-field magnetic-field characteristics of the half-wave dipole more intuitively, $\left|H_{y}\right|$ and $\left|H_{z}\right|$ distributions at $z=50 \mathrm{~mm}$ are shown in Fig. 4 (a) and Fig. 4 (b) respectively. The $\left|H_{z}\right|$ along $x$-axis are nearly zero that results in the blind area. The $\left|H_{y}\right|$ are weakening from center to sides, which is similar to the $\left|H_{z}\right|$ of the conventional loop antenna. So, the half-wave dipole placed along $x$-axis could read the tags that are set perpendicularly to the $y$-axis.

\subsection{Characteristics of the crossed half-wave dipoles}

In a similar way, the half-wave dipole along $y$-axis can identify the tags that are perpendicular to the $x$-axis. Inspired by this, the near-field reader antenna consisting of two crossed dipoles is proposed to identify the tags placed perpendicularly to the xoy plane. To verify the idea, suppose two ideal half-wave dipoles are perpendicular to each other and they have the same maximum current and initial phase, Fig. 5 displays its magnetic-field distributions of the $x, y$ and $z$ components respectively under $z=50 \mathrm{~mm}$.

Due to the superposition effects, the strength of $\left|H_{z}\right|$ along $y=x$ are weaker than that required to identify the tags.

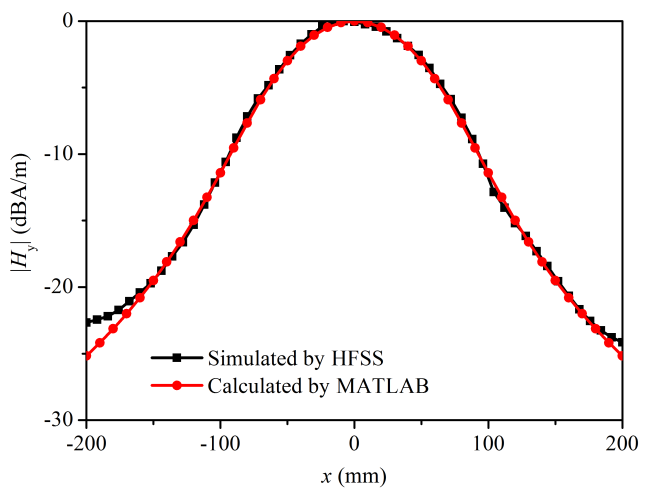

Fig. $3\left|H_{y}\right|$ distribution along $x$-axis at $z=50 \mathrm{~mm}$ 


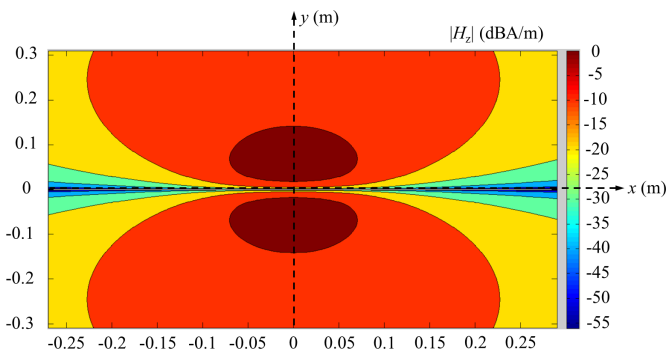

(a)

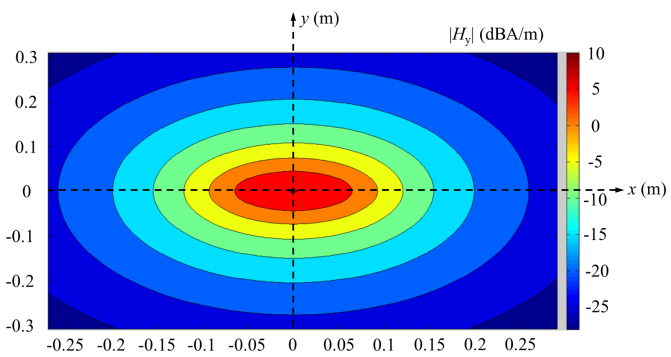

(b)

Fig. 4 Magnetic-field distributions of the half-wave dipole at $z=50 \mathrm{~mm}$ : (a) $\left|H_{z}\right|$; (b) $\left|H_{y}\right|$.

However, $\left|H_{x}\right|$ and $\left|H_{y}\right|$ have almost the same distribution that they have a relatively uniform and strong region right above the crossed dipoles surface. Hence, by theoretical analysis, the crossed dipoles can identify the tags that placed parallel to $z$-axis. Meanwhile, due to the simple structure, there are reasons to believe that the proposed antenna can be adapted well to the practical near-field RFID applications.

At the same time, from Fig. 5 (c), it can be found that the $\left|H_{z}\right|$ distribution of the proposed crossed half-wave dipoles looks like one dipole's distribution that placed along $y=x$. Thus, the crossed dipoles with the same source have the linear polarization. To verify this point, the simulated axisrate (AR) is shown in Fig. 6. It can be found that from 0.5 to $1.5 \mathrm{GHz}$, the AR is larger than $10 \mathrm{~dB}$. Usually, the antenna with AR less than $3 \mathrm{~dB}$ is considered as circularly polarized antenna.

\subsection{Optimization of structural parameter}

In order to achieve better performance, the proposed antenna is optimized by HFSS. In view of the complexity of design and fabrication, the feed network needs to be simple. Therefore, the maximum current and initial phase of the two crossed dipoles are kept the same. At the same time, since other parameters such as the widths of the dipole and feed have little impact on the near-field performance, only the length of the dipole should be optimized.

Adjusting the length $l_{2}$ showing in Fig. 1, the reflection coefficient $\left(S_{11}\right)$ of the proposed antenna is demonstrated in Fig. 7. With the length $l_{2}$ decreasing, the bandwidth broaden. When $l_{2}$ equals to $50 \mathrm{~mm}$, the bandwidth of $S_{11}<$ $-10 \mathrm{~dB}$ is about $260 \mathrm{MHz}$ from 830 to $1090 \mathrm{MHz}$. From this perspective, $l_{2}$ seems to be smaller to obtain the better performance.

While, for the near-field reader antenna, its magneticfield distribution is more important, which determines the recognition performance. With the help of HFSS, the input power is set as $30 \mathrm{dBm}$. $\left|H_{x}\right|$ and $\left|H_{y}\right|$ distributions along

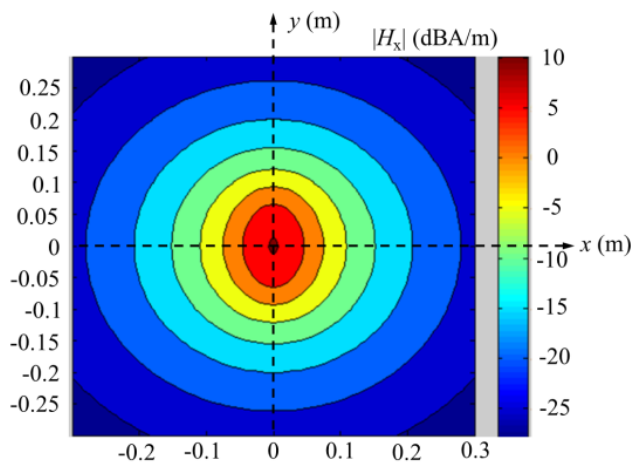

(a)

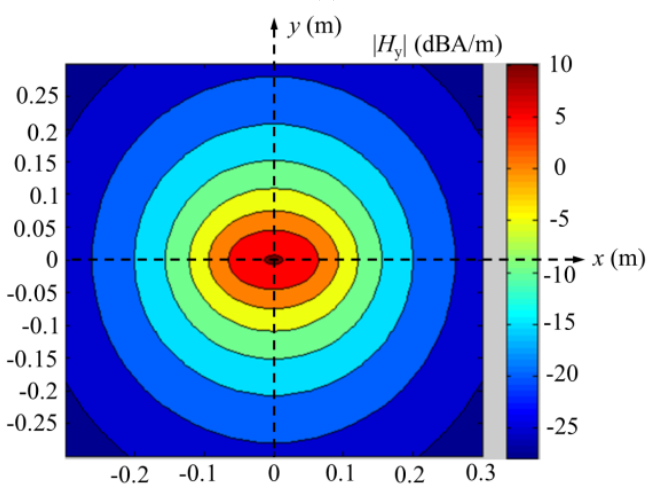

(b)

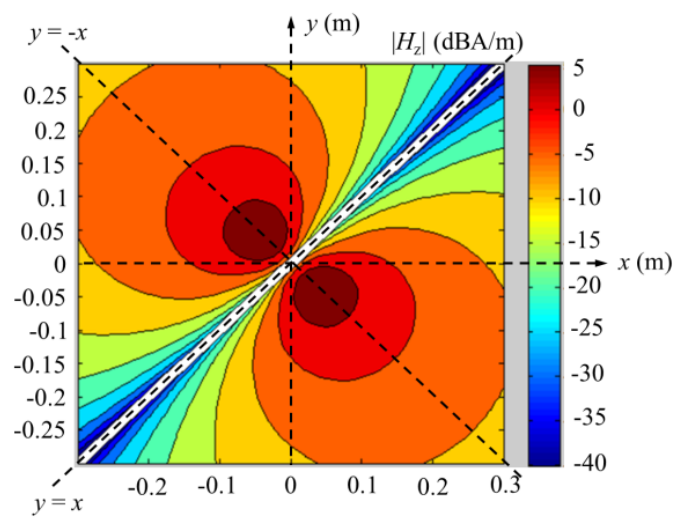

(c)

Fig. 5 Magnetic-field distributions of the crossed half-wave dipoles at $z=50 \mathrm{~mm}$ : (a) $\left|H_{x}\right|$; (b) $\left|H_{y}\right|$; (c) $\left|H_{z}\right|$.

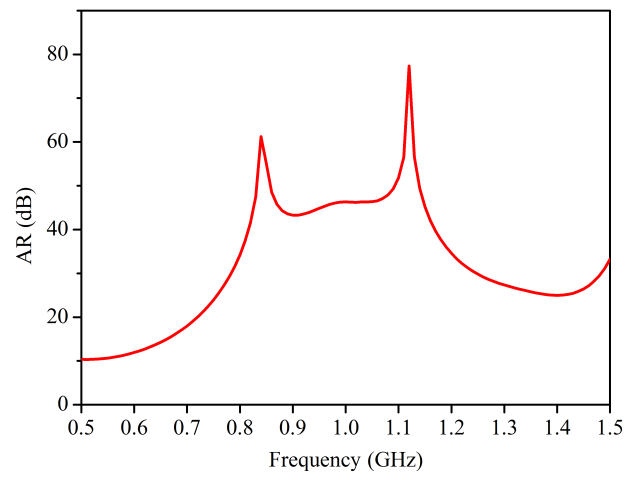

Fig. 6 The AR of crossed dipoles with the same source

$y$-axis are shown in Fig. 8 under the different length $l_{2}$. $\left|H_{x}\right|$ distributions are mainly affected by the dipole along $y$-axis, which the length does not change. Fig. 8 (a) shows 


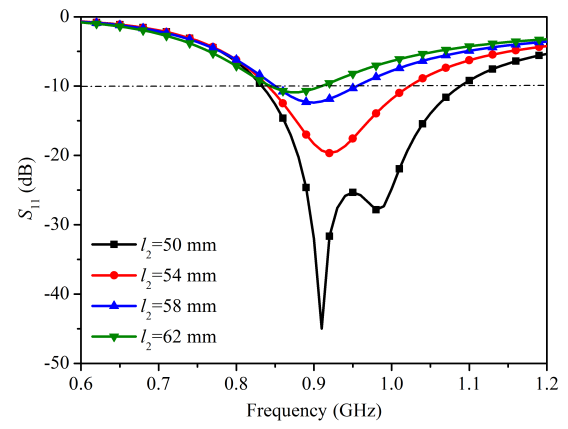

Fig. 7 Reflection coefficient curves under different length $l_{2}$

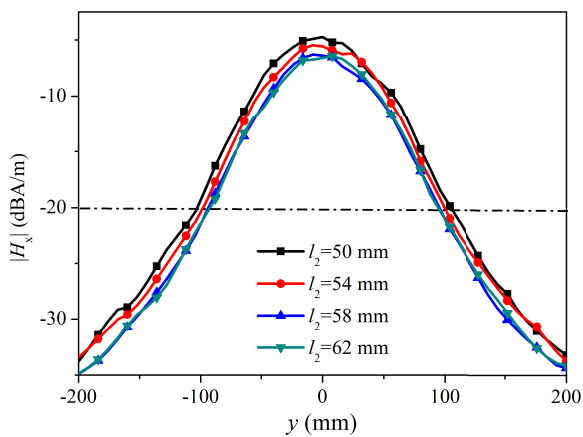

(a)

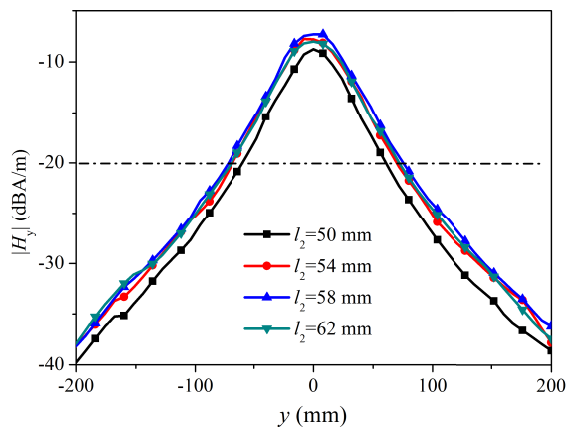

(b)

Fig. 8 Magnetic-field distributions along $y$-axis under different length $l_{2}$ : (a) $\left|H_{x}\right|$; (b) $\left|H_{y}\right|$.

that with $l_{2}$ decreasing, the strength of $\left|H_{x}\right|$ becomes larger, which means the other dipole's effect is reduced. Through Fig. 8 (b), it can be seen that the strength of $\left|H_{y}\right|$ at $l_{2}=$ $50 \mathrm{~mm}$ is the smallest, while under other conditions they are almost the same.

Considering the reflection coefficient and the magneticfield distribution, the length $l_{2}$ is optimized to be $54 \mathrm{~mm}$. At this point, the bandwidth is about $170 \mathrm{MHz}$ from 850 to $1020 \mathrm{MHz}$ that covers nearly all the UHF RFID frequency band of the world. Meanwhile, the $\left|H_{x}\right|$ and $\left|H_{y}\right|$ strength are both larger than $-20 \mathrm{dBA} / \mathrm{m}$ (the threshold strength to identify the tags) from $-70 \mathrm{~mm}$ to $70 \mathrm{~mm}$, which means the largest interrogation zone. Moreover, it can be found that the SMA connector can be directly connected the proposed antenna to achieve the impedance matching. In conclusion, the optimized antenna is simple in processing and has good performance.

\section{Experimental verification}

The proposed antenna was fabricated with the same dimen-

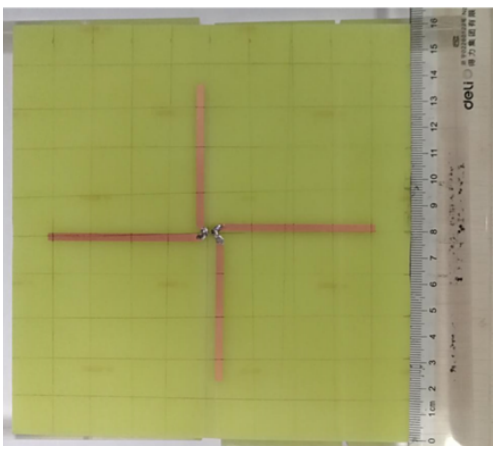

Fig. 9 Photograph of the fabricated antenna

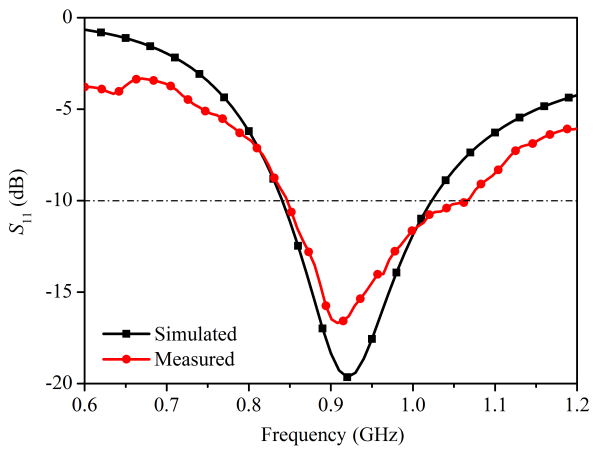

Fig. 10 Measured and simulated results of the reflection coefficient

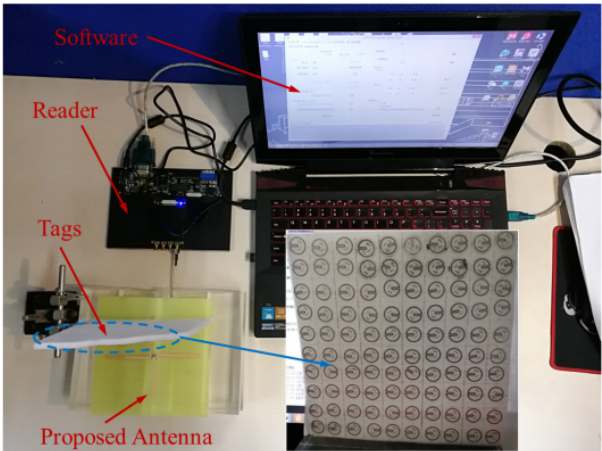

Fig. 11 Experiment device

sions as the simulated one $(160 \mathrm{~mm} \times 160 \mathrm{~mm} \times 1.6 \mathrm{~mm}$ in section 2), as shown in Fig. 9. The crossed dipoles are printed on the top of the substrate, and the SMA connector is directly connected at back.

With the help of a vector network analyzer, Fig. 10 gives the measured reflection coefficient of the proposed antenna. For comparison, the simulation results are added to the Fig. 10. It shows that the measured results are nearly consistent with the simulated ones. The measured $-10 \mathrm{~dB}$ bandwidth is about $210 \mathrm{MHz}$ (from 852 to $1062 \mathrm{MHz}$ ) and the corresponding relative bandwidth is about $21.9 \%$, which is larger than the conventional dipole and loop antenna.

To measure the interrogation zone, the experiment device is shown in Fig. 11. One hundred tags are uniformly attached to a piece of foam board with the dimension of $160 \mathrm{~mm} \times$ $160 \mathrm{~mm}$, which means that each tag takes up $16 \mathrm{~mm} \times 16 \mathrm{~mm}$ space. In the test process, by shifting the labeled foam board along the $x$-axis and $y$-axis respectively, the reading performance of the proposed antenna can be obtained. 


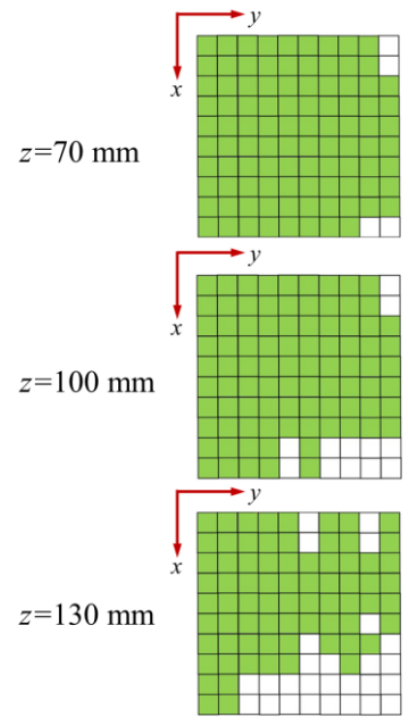

(a)

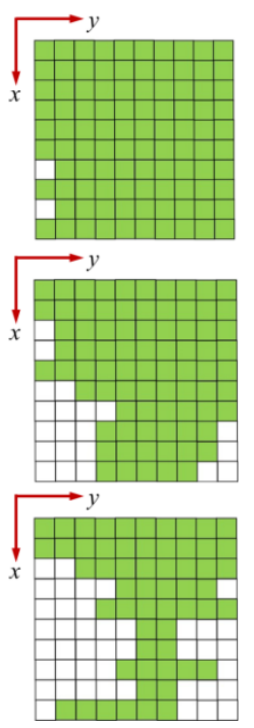

(b)
Fig. 12 Measured interrogation zones at different heights, (a) Labeled foam perpendicular to $x$-axis. (b) Labeled foam perpendicular to $y$-axis.

Fig. 12 gives the measured interrogation zones at different heights. In Fig. 12, each square represents a tag. The green square means that the tag in this location can be identified by the proposed antenna. While, the white one expresses that the proposed antenna cannot read the tag. As can be seen, with the tags away from the antenna surface, more tags cannot be identified. Through Fig. 12, about $9 \times 9$ tags are identified from the surface of the proposed antenna to $70 \mathrm{~mm}$ height, whether the labeled foam board is perpendicular to the $x$-axis or $y$-axis. Considering the occupied space of each tag, the interrogation zone of $100 \%$ tag detection is about $142 \mathrm{~mm} \times 142 \mathrm{~mm}$ under $70 \mathrm{~mm}$. Therefore, the experimental results also validate the reading performance of the proposed antenna.

\section{Conclusion}

A broadband cross dipole antenna has been proposed for the UHF near-field RFID applications. The proposed antenna is simple, and demonstrates high performance. The measured bandwidth about $210 \mathrm{MHz}(852-1062 \mathrm{MHz})$ covers the global UHF RFID frequency band. Meanwhile, the proposed antenna can identify the tags placed random perpendicularly to its surface with the interrogation zone of $142 \mathrm{~mm} \times 142 \mathrm{~mm}$. Such a design is more suitable for the special UHF near-field RFID applications.

\section{Acknowledgments}

This work was supported by the 333 Project Research Funding Project of Jiangsu Province (BRA2018315), Doctor Studio Project, Qing Lan Project, Natural Science Foundation of the Jiangsu Higher Education Institutions of China (19KJB510002), National Natural Science Foundation of China (61571232), Huai'an Innovation Service Capacity Construction Project (HAP201904).

\section{References}

[1] Q. Lei, et al.: "Design of a handheld UHF RFID reader for the internet of things," IEEE International Conference on Computer \& Management (2011) (DOI: 10.1109/CAMAN.2011.5778747).

[2] W. Bisheng, et al.: "Efficient identification UHF RFID system scheme based on combination of DFSA and OVSF-CDMA," IEICE Electron. Express 5 (2008) 954 (DOI: 10.1587/elex.5.954).

[3] S. Rao and J.-C. Chiao: "Body electric: wireless power transfer for implant applications," IEEE Microw. Mag. 16 (2015) 54 (DOI: 10.1109/MMM.2014.2377586).

[4] H. Yang, et al.: "Fully integrated UHF RFID mobile reader with power amplifiers using system-in-package (SiP)," IEICE Electron. Express 8 (2011) 83 (DOI: 10.1587/elex.8.83).

[5] C.-C. Huang, et al.: "Backscattering analysis of impedance loaded wire antenna for passive RFID applications," IEICE Electron. Express 7 (2010) 1169 (DOI: 10.1587/elex.7.1169).

[6] P.V. Nikitin, et al.: "An overview of near field UHF RFID," IEEE International Conference on RFID (2007) (DOI: 10.1109/RFID.2007. 346165).

[7] A. Michel, et al.: "Reconfigurable modular antenna for NF UHF RFID smart point readers,' IEEE Trans. Antennas Propag. 65 (2017) 498 (DOI: 10.1109/TAP.2016.2640140).

[8] W. Choi, et al.: "Near-field antenna for a radio frequency identification shelf in the UHF band," IET Microw. Antennas Propag. 4 (2010) 1538 (DOI: 10.1049/iet-map.2009.0203).

[9] X.P. Li, et al.: "Two-dimensional scanning antenna array for UHF radio frequency identification system application," IET Microw. Antennas Propag. 8 (2014) 1250 (DOI: 10.1049/iet-map.2014.0039).

[10] X.Y. Liu, et al.: "The UHF Gen 2 RFID system for transcutaenous operation for orthopedic implants," IEEE International Instrumentation \& Measurement Technology Conference (2013) (DOI: 10.1109/I2MTC.2013.6555688).

[11] (C) IDTechEx, Ltd.: "Near field UHF RFID vs HF for item level tagging," 2014.

[12] D.M. Dobkin, et al.: "Segmented magnetic antennas for near-field UHF RFID,” Microw. Journal 50 (2007) 96.

[13] X.M. Qing and Z.N. Chen: "UHF near-field segmented loop antennas with enlarged interrogation zone," IEEE International Workshop on Antenna Technology (2012) (DOI: 10.1109/IWAT.2012.6178416).

[14] X.M. Qing, et al.: "A UHF near-field/far-field RFID metamaterialinspired loop antenna," IEEE International Symposium on Antennas and Propagation (2012) (DOI: 10.1109/APS.2012.6349364).

[15] X.M. Qing, et al.: "UHF near-field RFID reader antenna with capacitive couplers," Electron. Lett. 46 (2010) 1591 (DOI: 10.1049/el. 2010.2762).

[16] A. Sharma, et al.: "Dual purpose near- and far-field UHF RFID coil antenna with non-uniformly distributed-turns," IEEE Antennas Wireless Propag. Lett. 14 (2015) 1342 (DOI: 10.1109/LAWP.2015. 2405016).

[17] X.M. Qing, et al.: "Segmented loop antenna for UHF near-field RFID applications,” Electron. Lett. 45 (2009) 872 (DOI: 10.1049/el. 2009.0326).

[18] X.M. Qing, et al.: "A broadband UHF near-field RFID antenna," IEEE Trans. Antennas Propag. 58 (2010) 3829 (DOI: 10.1109/TAP. 2010.2078432).

[19] J. Shi, et al.: "Electrically large zero-phase-shift line grid-array UHF near-field RFID reader antenna," IEEE Trans. Antennas Propag. 62 (2014) 2201 (DOI: 10.1109/TAP.2014.2299824).

[20] R. Pansomboon, et al.: "Improvement of multiple loop antenna for near-field UHF RFID applications," IEEE International Workshop on Electromagnetics (2014) (DOI: 10.1109/iWEM.2014.6963675).

[21] X.M. Qing, et al.: "Zero-phase-shift line antennas," IEEE International Workshop on Antenna Technology (2013) (DOI: 10.1109/ IWAT.2013.6518327).

[22] Y.J. Zeng, et al.: "Modeling and characterization of zero-phase-shift lines and optimization of electrically large ZPSL loop antennas for near-field systems," IEEE Trans. Antennas Propag. 64 (2016) 4587 (DOI: 10.1109/TAP.2016.2600703).

[23] Y.J. Zeng, et al.: "Design of a near-field nonperiodic zero phase 
shift-line loop antenna with a full dispersion characterization," IEEE Trans. Antennas Propag. 65 (2017) 2666 (DOI: 10.1109/TAP.2017. 2679061).

[24] Y.J. Zeng, et al.: "A directional, closely spaced zero-phase-shift-line loop array for UHF near-field RFID reader antennas," IEEE Trans. Antennas Propag. 66 (2018) 5639 (DOI: 10.1109/TAP.2018.2860619).

[25] X.M. Ding, et al.: "A novel magnetic coupling UHF near field RFID reader antenna based on multilayer-printed-dipoles array," IEEE Trans. Magn. 50 (2014) 1 (DOI: 10.1109/TMAG.2013.2273366).

[26] X.-D. Wei, et al.: "Novel UHF near-field RFID reader antenna based on double-sided parallel-strip line," IEEE Antennas Wireless Propag. Lett. 13 (2014) 419 (DOI: 10.1109/LAWP.2014.2308252).

[27] X.-D. Wei, et al.: "Novel broadband center-fed UHF near-field RFID reader antenna," IEEE Antennas Wireless Propag. Lett. 14 (2015) 703 (DOI: 10.1109/LAWP.2014.2377294).

[28] T.-H. Lin, et al.: "Compact UHF near-field RFID reader antenna," IEEE International Symposium of Antennas and Propagation (2014) (DOI: 10.1109/ISANP.2014.7026808).

[29] Z.N. Chen, et al.: "Loop antenna for UHF near-field RFID reader," Proceedings of the Fourth European Conference on Antennas and Propagation (2010).

[30] C.J. Ye, et al.: "A UHF near-field RFID system with contactless inductively coupled antenna," IEEE International Symposium on Radio-frequency Integration Technology (2012) (DOI: 10.1109/ RFIT.2012.6401637).

[31] Z. Frank: "Low profile near field antenna for RFID application," IEEE International Conference on Microwaves, Communications, Antennas and Electronic Systems (2008) (DOI: 10.1109/COMCAS. 2008.4562787).

[32] C. Cho, et al:: "Design of a novel ultra-high frequency radiofrequency identification reader antenna for near-field communications using oppositely directed currents," IET Microw. Antennas Propag. 4 (2010) 1543 (DOI: 10.1049/iet-map.2009.0232).

[33] C. Cho, et al.: "Planar near-field RFID reader antenna for itemlevel tagging," IEEE Antennas Wireless Propag. Lett. 10 (2011) 1100 (DOI: 10.1109/LAWP.2011.2169929).

[34] X.M. Ding, et al.: "A magnetic coupling dipole for UHF near-field RFID reader," IEEE Trans. Magn. 48 (2012) 4305 (DOI: 10.1109/ TMAG.2012.2199470).

[35] L.W. Shen, et al.: "Achieving uniform perpendicular magnetic field distribution for near-field ultra-high frequency radio-frequency identification," IET Microw. Antennas Propag. 10 (2016) 215 (DOI: 10.1049/iet-map.2015.0368).

[36] J.K. Pakkathillam, et al.: "A novel fractal antenna for UHF near-field RFID readers," IEEE Antennas Wireless Propag. Lett. 12 (2013) 1141 (DOI: 10.1109/LAWP.2013.2281069).

[37] Z.J. Xing and H.T. Li: "A planar reversed log-periodic UHF nearfield antenna for RFID applications," IEEE International Symposium on Antenna and Propagation (2017) (DOI: 10.1109/ISANP. 2017.8229060).

[38] H.T. Li, et al:: "A novel printed dual-log-periodic array antenna for UHF near-field RFID application," IEEE Trans. Antennas Propag. 66 (2018) 7418 (DOI: 10.1109/TAP.2018.2874202).

[39] A. Michel, et al.: "Multifunctional modular antenna for near-field ultra-high frequency radio frequency identification readers," IET Microw. Antennas Propag. 10 (2016) 843 (DOI: 10.1049/iet-map.2015. 0632).

[40] H.-W. Liu, et al.: "UHF reader loop antenna for near-field RFID applications," Electron. Lett. 46 (2010) 10 (DOI: 10.1049/el.2010.2868).

[41] A. Sharma, et al.: "Magnetic field forming using planar multicoil antenna to generate orthogonal H-field components," IEEE Trans. Antennas Propag. 65 (2017) 2906 (DOI: 10.1109/TAP.2017.2695009). 